\title{
Dimethylammonium iodide stabilized bismuth halide perovskite photocatalyst for hydrogen evolution
}

\author{
He Zhao ${ }^{1}$, Kalyani Chordiya ${ }^{2,3}$, Petri Leukkunen ${ }^{4}$, Alexey Popov ${ }^{5, \dagger}$, Mousumi Upadhyay Kahaly ${ }^{2,3}$, Krisztian Kordas $^{6}(\bowtie)$, \\ and Satu Ojala ${ }^{1}(\square)$ \\ ${ }^{1}$ Environmental and Chemical Engineering Research Unit, University of Oulu, P. O. Box 4300, FI-90014 Oulu, Finland \\ ${ }^{2}$ ELI-ALPS, ELI-HU Non-Profit Ltd., Dugonics ter 13, 6720 Szeged, Hungary \\ ${ }^{3}$ Institute of Physics, University of Szeged, Dóm tér 9, H-6720 Szeged, Hungary \\ ${ }^{4}$ Nano and Molecular Systems Research Unit, University of Oulu, P.O. Box 3000, FI-90014 Oulu, Finland \\ ${ }^{5}$ Optoelectronics and Measurement Techniques Unit, University of Oulu, FI-90570 Oulu, Finland \\ ${ }^{6}$ Microelectronics Research Unit, University of Oulu, P. O. Box 4500, FI-90014 Oulu, Finland \\ ${ }^{\dagger}$ Present address: VTT Technical Research Centre of Finland, FI-90590 Oulu, Finland
}

(C) The Author(s) 2020

Received: 24 August 2020 / Revised: 30 September 2020 / Accepted: 4 October 2020

\begin{abstract}
Metal halide perovskites have emerged as novel and promising photocatalysts for hydrogen generation. Currently, their stability in water is a vital and urgent research question. In this paper a novel approach to stabilize a bismuth halide perovskite $\left[\left(\mathrm{CH}_{3}\right)_{2} \mathrm{NH}_{2}\right]_{3}\left[\mathrm{Bil}{ }_{6}\right]$ $\left(\mathrm{DA}_{3} \mathrm{Bil}_{6}\right)$ in water using dimethylammonium iodide (DAl) without the assistance of acids or coatings is reported. The $\mathrm{DA}_{3} \mathrm{Bil}_{6} \mathrm{powder}$ exhibits good stability in DAl solutions for at least two weeks. The concentration of DAl is found as a critical parameter, where the $\mathrm{I}^{-}$ions play the key role in the stabilization. The stability of $\mathrm{DA}_{3} \mathrm{Bil}_{6}$ in water is realized via a surface dissolution-recrystallization process. Stabilized $\mathrm{DA}_{3} \mathrm{Bil}_{6}$ demonstrates constant photocatalytic properties for visible light-induced photo-oxidation of $\mathrm{I}^{-}$ions and with $\mathrm{PtCl}_{4}$ as a co-catalyst $\left(\mathrm{Pt}_{-} \mathrm{DA}_{3} \mathrm{Bil}_{6}\right)$, photocatalytic $\mathrm{H}_{2}$ evolution with a rate of $5.7 \mu \mathrm{mol} \cdot \mathrm{h}^{-1}$ from $\mathrm{HI}$ in DAl solution, obtaining an apparent quantum efficiency of $0.83 \%$ at $535 \mathrm{~nm}$. This study provides new insights on the stabilization of metal halide perovskites for photocatalysis in aqueous solution.
\end{abstract}

\section{KEYWORDS}

bismuth halide perovskite, dimethylammonium iodide, photocatalysis, hydrogen evolution

\section{Introduction}

Hydrogen evolution from solar-driven splitting of water or acids has been regarded as a promising approach for the conversion and storage of solar energy, and thus it has been under the scope of research for nearly half a century [1-3]. Until today, the typical photocatalysts have been rather inefficient because of their large band gap or severe recombination of photocarriers $[4,5]$. More recently, metal halide perovskites have been widely employed as efficient photoactive materials in solar cells, with a surge of power conversion efficiency from $3.8 \%$ to exceeding $25.2 \%$ over the past decade $[6,7]$. The exceptional performance in solar cells originates from their superior optoelectronic properties, such as wide absorption window and long electron-hole diffusion lengths [8-10], which are also highly expected among photocatalysts. For the first time, Nam et al. reported their pioneering work of photocatalytic hydroiodic acid (HI) splitting using methylammonium lead iodide $\left(\mathrm{MAPbI}_{3}\right)$ [11]. To date, because of the instability of hybrid perovskites in water, all photocatalytic hydrogen evolution reactions on lead based perovskites are carried out in concentrated hydrohalic acids [11-19]. Moreover, despite their superior light-harvesting and carrier transporting properties, the high cost and corrosive nature of concentrated hydrohalic acids as well as the environmental and health risks associated with lead make such processes for $\mathrm{H}_{2}$ evolution impractical and have thus largely limited their general applications in photocatalysis [20, 21].

Approaches have been developed to replace lead and alleviate the problem of perovskite instability simultaneously using e.g. all-inorganic halide perovskites and bismuth halide perovskites. In particular, bismuth halide perovskites have shown better stability under ambient atmosphere in solar cells in comparison with traditional lead based perovskites [22]. Although some works have demonstrated that the bismuth halide hybrids show catalytic activity in lower concentration of hydrohalic acids or even water $[23,24]$, their stability issue in aqueous solution is still lacking. In addition, encapsulation strategy has been explored to stabilize metal halide perovskites in water $[25,26]$. However, for coating approach, one needs to consider many aspects such as the thickness, chemistry and charge transport behavior of the shell material to ensure the photogenerated carriers can eventually reach the surface and react with adsorbed species there $[27,28]$. Considering mentioned above, stabilizing bismuth-based halide perovskites directly in water is a challenging but meaningful route for widening the photocatalytic applications with copious water.

More recent years, the dimethylammonium iodide (DAI)- 
related methods are widely used to stabilize the perovskite phase $[29,30]$. It has been reported that the incorporation of DAI into perovskite solar cells can improve the air and thermal stability as well as charge transport property [31-33]. Notably, the stabilization with DAI seems more promising than the use of insulating coating materials in photocatalysis because the latter may hinder the charge transfer from perovskite to surface catalytic sites and deteriorate the following redox reactions [34, 35]. However, to the best of our knowledge, there is no report on stabilizing bismuth halide perovskite in aqueous solution with DAI so far. Herein, we present a facile strategy to synthesize a lead-free hybrid semiconducting perovskite $\left[\left(\mathrm{CH}_{3}\right)_{2} \mathrm{NH}_{2}\right]_{3}\left[\mathrm{BiI}{ }_{6}\right]$ $\left(\mathrm{DA}_{3} \mathrm{BiI}_{6}\right)$ and its improved stability in acid-free aqueous DAI solutions without coatings for the first time. As a result, the $\mathrm{DA}_{3} \mathrm{BiI}_{6}$ powder displays good water-tolerance in DAI solutions for two weeks without degradation and exhibits stable photocatalytic properties in DAI solutions.

\section{Experimental}

\subsection{Materials}

Dimethylamine $\left(\left(\mathrm{CH}_{3}\right)_{2} \mathrm{NH}, 40 \%\right.$ solution in water $)$, $\mathrm{HI}(57 \%$ solution in water, unstabilized), methylamine $\left(\mathrm{CH}_{3} \mathrm{NH}_{2}, 40 \%\right.$ solution in water), diethyl ether ( $\geq 99.5 \%)$, ethanol absolute (99.96\%), bismuth sulfide $\left(\mathrm{Bi}_{2} \mathrm{~S}_{3}, 99.9 \%\right)$, dimethylformamide (DMF, anhydrous, 99.8\%), chloroform (anhydrous, $\geq 99 \%$, containing $0.5 \%-1.0 \%$ ethanol as stabilizer), acetonitrile (anhydrous, $99.8 \%$ ), potassium iodide (KI, ACS reagent, $\geq 99 \%)$, iodine $\left(I_{2}\right.$, ACS reagent, $\geq 99.8 \%$ ), platinum(IV) chloride $\left(\mathrm{PtCl}_{4}, \geq 99.99 \%\right)$ and hypophosphorous acid $\left(\mathrm{H}_{3} \mathrm{PO}_{2}, 50 \%\right.$ solution in water $)$ were used as received.

\subsection{Synthesis of DAI}

DAI was synthesized by adding $32.3 \mathrm{~mL}$ of $\mathrm{HI}$ solution dropwise in $28.5 \mathrm{~mL}$ of $\left(\mathrm{CH}_{3}\right)_{2} \mathrm{NH}$ in a round-bottom flask, and then stirred at $0{ }^{\circ} \mathrm{C}$ for $2 \mathrm{~h}$ in ice-water. To collect the product, the excess solvent was removed using a rotary evaporator at $60{ }^{\circ} \mathrm{C}$ for $2 \mathrm{~h}$. The obtained brown solid was washed with diethyl ether until colorless solid was obtained. Then, the powder was recrystallized in the mixture of diethyl ether and absolute ethanol $(1: 5 \mathrm{v} / \mathrm{v})$ for $24 \mathrm{~h}$. After filtration, a white powder (DAI) was collected and dried at $60^{\circ} \mathrm{C}$ for $24 \mathrm{~h}$. A similar procedure was utilized to synthesize methylammonium iodide (MAI) except that $19.5 \mathrm{~mL}$ of $\mathrm{CH}_{3} \mathrm{NH}_{2}$ was used.

\subsection{Synthesis of $\mathrm{DA}_{3} \mathrm{BiI}_{6}$ and bismuth triiodide $\left(\mathrm{BiI}_{3}\right)$}

$0.103 \mathrm{~g}$ of $\mathrm{Bi}_{2} \mathrm{~S}_{3}$ was dissolved in $2 \mathrm{~mL}$ of $\mathrm{HI}$ solution by stirring for $10 \mathrm{~min}$, and the obtained red solution was filtered through a $0.45 \mu \mathrm{m}$ polytetrafluoroethylene (PTFE) syringe filter. Next, the solution was added into $12 \mathrm{~mL}$ of absolute ethanol and $800 \mu \mathrm{L}$ of DMF and heated at $80^{\circ} \mathrm{C}$ (in water bath) under continuous stirring for $2 \mathrm{~h}$. Finally, the obtained dark red solution was transferred into a baker and sealed, then cooled at room temperature overnight for crystallization. The $\mathrm{DA}_{3} \mathrm{BiI}_{6}$ powder was collected with a paper filter $(2 \mu \mathrm{m})$ and washed with chloroform until the solution was colorless. The resultant orange powder was dried at room temperature for $24 \mathrm{~h}$. $\mathrm{BiI}_{3}$ was synthesized by the reaction of bismuth trioxide $\left(\mathrm{Bi}_{2} \mathrm{O}_{3}\right)$ and hydriodic acid with 1:1 molar ratio, followed by centrifuging $(8,000 \mathrm{rpm}, 3 \mathrm{~min})$ and drying at $60^{\circ} \mathrm{C}$ overnight.

\subsection{Solubility of $\mathrm{DA}_{3} \mathrm{BiI}_{6}$ in $\mathrm{HI}$ solution}

The solubility was determined by analyzing the supernatant fraction of saturated solutions of $\mathrm{DA}_{3} \mathrm{BiI}_{6}$ powder. In brief, $250 \mathrm{mg}$ of $\mathrm{DA}_{3} \mathrm{BiI}_{6}$ powder was added into $1 \mathrm{~mL}$ of $\mathrm{HI}$ solution, followed by sonication and shaking simultaneously for $30 \mathrm{~min}$. Next, the upper clear fraction of the liquid was collected and filtered (0.45 $\mu \mathrm{m}$ PTFE), and then kept stand-still overnight. After that, a washed glass slide (weight: $W_{1}$ ) was chosen as a carrier. $10 \mu \mathrm{L}$ of the upper liquid was dropped on it and thermally annealed in oven at $110{ }^{\circ} \mathrm{C}$ for $30 \mathrm{~min}$ (weight: $W_{2}$ ). The solubility was calculated by the mass difference $\left(W_{2}-W_{1}\right)$.

\subsection{Amount of evolved triiodide $\left(\mathrm{I}_{3}{ }^{-}\right)$ions}

Firstly, the standard curve of $\mathrm{I}_{3}{ }^{-}$solutions was obtained by plotting the UV-vis absorption data $(351 \mathrm{~nm})$ of $\mathrm{I}_{3}{ }^{-}$ions at various concentrations. An iodine solution $(0.001 \mathrm{M})$ was obtained by the dissolution of $12.6 \mathrm{mg}$ of solid iodine into $50 \mathrm{~mL}$ of $0.18 \mathrm{M}$ KI solution. Then different concentration of $\mathrm{I}_{3}$ solution was synthesized by mixing the iodine solution $(0.001 \mathrm{M})$ and the KI solution $(0.01 \mathrm{M})$. The corresponding concentration of $\mathrm{I}_{3}{ }^{-}$ions was determined by the iodine solution because of the introduction of extra iodide ions in solution to stabilize $\mathrm{I}_{3}$ ions. The fresh $\mathrm{I}_{3}{ }^{-}$solutions were characterized with UV-vis spectrophotometer. Notably, the stock solution should be fresh because the $\mathrm{I}_{3}{ }^{-}$ions may be disproportionated into $\mathrm{I}_{3}{ }^{-}$and $\mathrm{IO}_{3}{ }^{-}$ ions in water and the KI solution is not stable when exposed to light. Then, the concentrations of $\mathrm{I}_{3}{ }^{-}$ions before and after light irradiation were determined by the standard curve mentioned above. Owing to the similar absorption range caused by iodobismuthate ions in photocatalytic solutions, a $1 / 100$ dilution with water of stock solution was used to determine the concentration of $\mathrm{I}_{3}{ }^{-}$ions.

\subsection{Characterization}

The morphology of $\mathrm{DA}_{3} \mathrm{BiI}_{6}$ powder was analyzed by field emission scanning electron microscopy (FESEM, Zeiss Sigma FESEM). Powder X-ray diffraction (XRD) was carried out by using PANalytical X'Pert Pro Diffractometer with $\mathrm{Cu} \mathrm{K} \alpha$, at $2 \theta$ scan from $5^{\circ}$ to $80^{\circ}$. Attenuated total reflection Fourier-transform infrared (ATR-FTIR) spectra were recorded with a Bruker HYPERION 3000 FT-IR Microscope equipped with ATR crystal. X-ray photoelectron spectroscopy (XPS) was obtained by using a Thermo Fisher Scientific ESCALAB 250Xi instrument with $\mathrm{Al} \mathrm{K \alpha}$ irradiation. The spectrometer work function used was $4.59 \mathrm{eV}$. The binding energy of aliphatic C1s peak $(284.8 \mathrm{eV})$ was applied as reference for calibration. Absorption spectra of solutions were collected using a UV-vis spectrophotometer (UV-2600, SHIMADZU). The absorption spectrum of solid was recorded with a spectrophotometer system (Optronic Laboratories, USA) equipped with an integrating sphere. The experimental bandgap was determined from the Tauc plot for indirect transition $\left(h v \sim(\alpha h v)^{1 / 2}\right.$, where $h v$ is the photon energy and $\alpha$ is the optical absorption coefficient). The light-emitting diode (LED) spectra were analyzed using Ocean Optics USB4000 spectrometer and the light intensity was measured by the Compact Power and Energy Meter Console (PM100D) equipped with a power sensor head (THORLABS, S310C).

\subsection{Density functional theory (DFT) calculations}

The electronic structure calculations were based on the experimental lattice parameters $(a=b=30.8173 \AA$ and $c=8.8171 \AA$ ) of the crystal structure of $\mathrm{DA}_{3} \mathrm{BiI}_{6}$ [23]. All the DFT calculations were carried out using Quantum-ESPRESSO package [36]. Total energy calculations were performed within the linear density approximation (LDA), using Perdew-Zunger (PZ) exchange-correlation functional. $\mathrm{H}(1 \mathrm{~s}, 2 \mathrm{p}, 3 \mathrm{~d}, 4 \mathrm{f}), \mathrm{C}(2 \mathrm{~s}, 2 \mathrm{p}$, $3 \mathrm{~d}, 4 \mathrm{f}), \mathrm{N}(2 \mathrm{~s}, 2 \mathrm{p}, 3 \mathrm{~d}, 4 \mathrm{f}), \mathrm{I}(5 \mathrm{~s}, 5 \mathrm{p}, 5 \mathrm{~d}, 4 \mathrm{f})$ and Bi (6s, 6p, 6d, 5f) orbitals were treated as valence orbitals. Since the crystal unit cell was large, a $2 \times 2 \times 4 k$-point mesh was used to 
sample the Brillouin-zone of the crystal. The results of the calculations were checked for convergence with respect to the number of $k$ points and the plane wave cut off energy. After the full relaxation of $\mathrm{DA}_{3} \mathrm{BiI}_{6}$, followed by self-consistent field calculations for total electronic densities of states (DOS), nonself-consistent field calculations along symmetry directions $\Gamma-\mathrm{K}-\mathrm{H}-\Gamma$ was performed for its electronic band structure analysis. The reorganization energy ( $\lambda_{\mathrm{i}}, \mathrm{i}$ is hole or electron) was calculated based on Marcus theory [37, 38], using the following equation [39]

$$
\lambda_{i}=\left(E_{0}^{ \pm}-E_{ \pm}\right)+\left(E_{ \pm}^{0}-E_{0}\right)
$$

where $E_{0}^{ \pm}$is the energy of ion calculation with the geometry of the neutral molecules, $E_{ \pm}$is the energy of ion in ion geometry. $E_{ \pm}^{0}$ is the energy of neutral molecules in ion state, and $E_{0}$ is the energy of neutral molecule at ground state geometry.

\subsection{Photocatalytic reactions}

The photocatalytic reactions were performed in a quartz vial $(40 \mathrm{~mL})$ equipped with a cooling system $\left(6{ }^{\circ} \mathrm{C}\right)$ under a commercial white LED lamp (Blue Import BIM, LED, $100 \mathrm{~W}$ ). The light intensity was $76.4 \mathrm{~mW} \cdot \mathrm{cm}^{-2}$ at a distance of $48 \mathrm{~mm}$ and the total optical power impinging on the solution was determined to be $422 \mathrm{~mW}$. The photooxidation of $\mathrm{I}^{-}$ions to $\mathrm{I}_{3}{ }^{-}$ ions was conducted in $10 \mathrm{~mL}$ of DAI solution with or without $\mathrm{DA}_{3} \mathrm{BiI}_{6}$ powders and the evolved $\mathrm{I}_{3}{ }^{-}$ions were determined by UV-vis spectroscopy after irradiation. For hydrogen evolution, the same system was used. Typically, $4 \mathrm{~mL}$ of $\mathrm{H}_{3} \mathrm{PO}_{2}$ was mixed with different amount of $\mathrm{HI}$, and the overall reaction solution was kept as $10 \mathrm{~mL}$ by adjusting the amount of DAI solution. Then, a desired amount of $\mathrm{DA}_{3} \mathrm{BiI}_{6}$ and $1 \mathrm{mg}$ of $\mathrm{PtCl}_{4}$ powder were added into the above mixture, followed by degassing with $\mathrm{N}_{2}$ gas for $30 \mathrm{~min}$. The solution was irradiated with the commercial white LED lamp for $1 \mathrm{~h}$ under continuous magnetic stirring. The evolved hydrogen was analyzed with a Micro GC (Agilent 490G, MolSieve $5 \AA$ column, with argon gas as carrier).

The repeatability tests for $\mathrm{H}_{2}$ evolution were carried out by four consecutive photocatalytic experiments. Each time the reactor was irradiated with the white LED source for $1 \mathrm{~h}$, and then bubbled with $\mathrm{N}_{2}$ for 10 min before the next cycle. After every run $(4 \mathrm{~h})$, the solution was kept overnight and then bubbled with $\mathrm{N}_{2}$ for $30 \mathrm{~min}$ before the next photocatalytic reaction.

The apparent quantum efficiency (AQE) was determined under different monochromatic LED lamp (420, 450, 485 and $535 \mathrm{~nm}$ ) from multichannel photochemical reaction device (PCX50B Discover, Beijing Perfect light Co. Ltd.). The measured light intensities were $41.7,44.6,18.8$ and $13.3 \mathrm{~mW} \cdot \mathrm{cm}^{-2}$, respectively. The reflectivity on the quartz-air interface was calculated from the Fresnel equation for normal incidence and thus about $4 \%$ of the incident intensity was reflected. The modified incident light intensities were 40.0, 42.8, 18.0 and $12.8 \mathrm{~mW} \cdot \mathrm{cm}^{-2}$ without considering the loss of intensity at quartzto-solution interface. The AQE values were calculated according to the following formula [14]

$$
\mathrm{AQE}=\frac{2 N\left(\mathrm{H}_{2}\right)}{N(\text { photons })} \times 100
$$

where $N\left(\mathrm{H}_{2}\right)$ is the number of evolved $\mathrm{H}_{2}$ molecules and $N$ (photons) is the number of incident photons.

\section{Results and discussion}

\subsection{Structure and morphology}

Here we report a novel solution-processed method for the synthesis of $\mathrm{DA}_{3} \mathrm{BiI}_{6}$ powder at $80{ }^{\circ} \mathrm{C}$ for $2 \mathrm{~h}$ (see details in Experimental section). This method is much easier than those of previously reported in Refs. [23, 40, 41], which were processed under solvothermal conditions or lasted for three months. The morphology of $\mathrm{DA}_{3} \mathrm{BiI}_{6}$ powder characterized by FESEM reveals rod-like crystals with smooth facets (Fig. 1(a)), similar to those reported using a solvothermal method [23]. According to the XRD analysis (Fig. 1(b)), the diffraction pattern of the product matches well with the previously reported rhombohedral $\mathrm{DA}_{3} \mathrm{BiI}_{6}[23,40]$. The elemental composition and oxidation states (a)

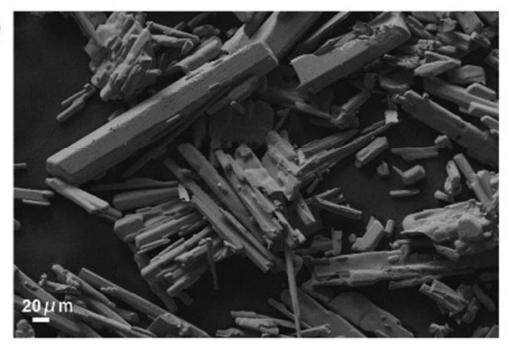

(c)

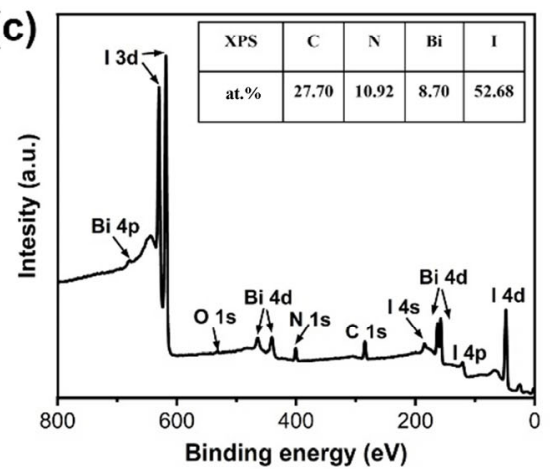

(b)

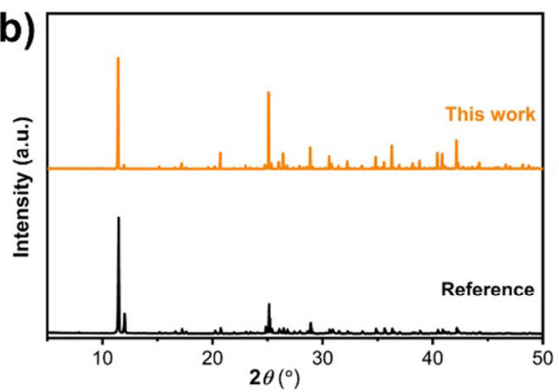

(d)

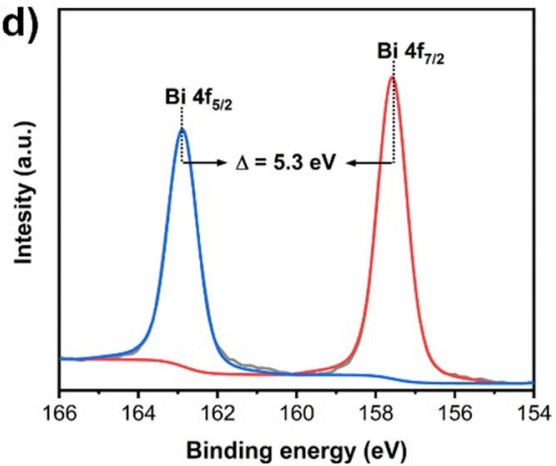

Figure 1 Morphology and structural characterizations of $\mathrm{DA}_{3} \mathrm{BiI}_{6}$ powder. (a) FESEM image of $\mathrm{DA}_{3} \mathrm{BiI}_{6}$ powder. (b) XRD patterns of DA $\mathrm{XBI}_{6}$ powder from this work and from Ref. [23]. (c) X-ray photoelectron spectrum (survey) of $\mathrm{DA}_{3} \mathrm{BiI}_{6}$ powder. The inset table shows the atomic ratio of element obtained from the spectrum. (d) Resolved Bi 4 f peak of $\mathrm{DA}_{3} \mathrm{BiI}_{6}$ powder. 
of $\mathrm{Bi}$ of the product were further confirmed by XPS (Fig. 1(c)) revealing the presence of $\mathrm{C}, \mathrm{N}, \mathrm{Bi}$ and $\mathrm{I}$ with an atomic ratio of 6.05 for I/Bi (inset in Fig. 1(c)), which is consistent with the stoichiometric value in $\mathrm{DA}_{3} \mathrm{BiI}_{6}$ as well as the result from energy dispersive X-ray spectroscopy (EDS, Fig. S1 in the Electronic Supplementary Material (ESM)). The O 1s signal at $531.9 \mathrm{eV}$ may originate from adsorbed $\mathrm{O}_{2}$ or ambient moisture [42]. The Bi $4 \mathrm{f}$ spectrum shows the characteristic binding energy located at 157.6 and $162.9 \mathrm{eV}$ with a corresponding spin-orbit splitting of $5.3 \mathrm{eV}$ (Fig. 1(d)) indicating $\mathrm{Bi}^{3+}$ oxidation state in the product [43]. Combining the above analysis, it can be concluded that $\mathrm{DA}_{3} \mathrm{BiI}_{6}$ is synthesized successfully using a simple method that does not require autoclaves and elevated pressures as in solvothermal synthesis or long reaction period.

\subsection{Stability of $\mathrm{DA}_{3} \mathrm{BiI}_{6}$ in DAI solution}

Due to the ionic characteristics, halide perovskites generally exhibit extreme sensitivity to polar solvents, especially water. For instance, once $\mathrm{MAPbI}_{3}$ is in contact with water, it starts to decompose, forming $\mathrm{MA}^{+}, \mathrm{I}^{-}$ions and $\mathrm{PbI}_{2}$. From the viewpoint of chemical reaction, the low solubility of $\mathrm{PbI}_{2}$ in water is the main obstacle to rebuild $\mathrm{MAPbI}_{3}$ molecules, while the formation of $\mathrm{PbI}_{3}{ }^{-}$ions in water from the reaction of $\mathrm{PbI}_{2}$ and $\mathrm{I}^{-}$ions seems promising to stabilize halide perovskites in water. Zheng et al. proposed that the removal of $\mathrm{I}^{-}$ions from the surface of $\mathrm{MAPbI}_{3}$ triggers the initial dissolution of $\mathrm{MAPbI}_{3}$ in water [44]. On the other hand, degraded $\mathrm{MAPbI}_{3}$ can be regenerated through a treatment with MAI or $\mathrm{I}_{2}$ solution $[45,46]$. Such observations suggest that controlling the concentration of DAI might stabilize $\mathrm{DA}_{3} \mathrm{BiI}_{6}$ in water.

As shown in Fig. 2(a), a series of aqueous DAI solutions, with concentrations up to $0.25 \mathrm{M}$ were prepared and equal amounts of $\mathrm{DA}_{3} \mathrm{BiI}_{6}$ powder were added. In water, the $\mathrm{DA}_{3} \mathrm{BiI}_{6}$ powder decomposed into $\mathrm{BiI}_{3}$ immediately and the color of the powder changed from orange to black (see Fig. S2 in the ESM) whereas no visibly black-colored substance was observed in the presence of DAI, implying directly that DAI molecules can hamper the degradation of $\mathrm{DA}_{3} \mathrm{BiI}_{6}$ in water. The possible reason is that the addition of DAI to water leads to the dissolution of $\mathrm{BiI}_{3}$ and formation of iodobismuthate(III) ions $\left(\mathrm{BiI}_{4}{ }^{-}, \mathrm{BiI}_{6}{ }^{3-}\right.$ or $\left.\mathrm{BiI}_{7}{ }^{4-}\right)$ [47], thus stabilizing $\mathrm{DA}_{3} \mathrm{BiI}_{6}$ powder in water. To verify this hypothesis, after 1-day immersion, a 1/10 dilution of solution (Fig. 2(b)) with acetonitrile was prepared and identified using UV-vis absorption spectroscopy. The spectral changes are displayed in Fig. 2(c). In water, no apparent absorption appeared between 300 and $600 \mathrm{~nm}$, which are the characteristic absorption ranges of iodobismuthate(III) ions, implying the rather high stability of $\mathrm{BiI}_{3}$ in water. Increasing the DAI concentration to $0.05 \mathrm{M}$, the aqueous solution turned to yellow, which indicates the appearance of iodobismuthate(III) ions. Besides, two peaks appeared to UV-vis spectra located at 350 and $461 \mathrm{~nm}$, which can be assigned to $\left[\mathrm{BiI}_{4}\right]^{-}$ions and $\mathrm{BiI}_{3}$ (Figs. S3 and S4 in the ESM), respectively [48]. Upon further increase of the DAI concentration (up to $0.15 \mathrm{M}$ ), the absorption peaks became stronger, suggesting the increasing amount of iodobismuthate(III) ions. Meanwhile, the peaks gradually shifted to 347 and $483 \mathrm{~nm}$, that are reasonably ascribed to the characteristic peaks of $\mathrm{BiI}_{6}{ }^{3-}$ ions [48]. The difference ( $347 \mathrm{~nm}$ vs. $350 \mathrm{~nm}$ and $483 \mathrm{~nm}$ vs. $486 \mathrm{~nm}$ ) for the peak positions may result from the presence of DAI in the aqueous solution, which is known to have a great effect on the absorption spectra [49]. The gradual shift of absorption peaks also suggests a stepwise $\mathrm{BiI}_{3} \rightarrow\left[\mathrm{BiI}_{4}\right]^{-} \rightarrow\left[\mathrm{BiI}_{6}\right]^{3-}$ transformation with the increase of DAI concentration. Above $0.15 \mathrm{M}$ of DAI in the solution, no further peak shift in the spectra was observed, indicating that only $\mathrm{BiI}_{6}{ }^{3-}$ ions were present. In addition, no peaks above $500 \mathrm{~nm}$ appeared, precluding the existence of $\mathrm{BiI}_{7}^{4-}$ ions in our current system [47].

To understand how DAI molecules stabilize $\mathrm{DA}_{3} \mathrm{BiI}_{6}$ in water (i.e. to confirm the role of $\left(\mathrm{CH}_{3}\right)_{2} \mathrm{NH}_{2}{ }^{+}$and $\mathrm{I}^{-}$ions in stabilization of $\mathrm{DA}_{3} \mathrm{BiI}_{6}$ ), three solutions were prepared: (1) $0.2 \mathrm{M}$ aqueous dimethylamine, (2) $0.2 \mathrm{M}$ aqueous $\mathrm{KI}$, and (3) $0.2 \mathrm{M}$ aqueous MAI. As shown in Fig. S5 in the ESM, the $\mathrm{DA}_{3} \mathrm{BiI}_{6}$ powder was deliberately immersed in water to obtain $\mathrm{BiI}_{3}$. Then, the $\mathrm{BiI}_{3}$ powder was collected and transferred into the above three solutions. Note that the black color of the powder turned into red in $0.2 \mathrm{M} \mathrm{KI}$ and $0.2 \mathrm{M}$ aqueous MAI, whereas the color of solutions turned to yellow. The characteristic absorption peaks of $\mathrm{BiI}_{6}{ }^{3-}$ ions were also detected (Fig. 2(d)), implying that the $\mathrm{I}^{-}$ions reacted with $\mathrm{BiI}_{3}$. In contrast, white powder was obtained in $0.2 \mathrm{M}$ dimethylamine aqueous solution and $\mathrm{BiI}_{6}{ }^{3-}$ was not formed according to UV-vis absorption spectra. These observations mean that $\mathrm{I}^{-}$ions play an important role in the stabilization. On the basis of the above results, we
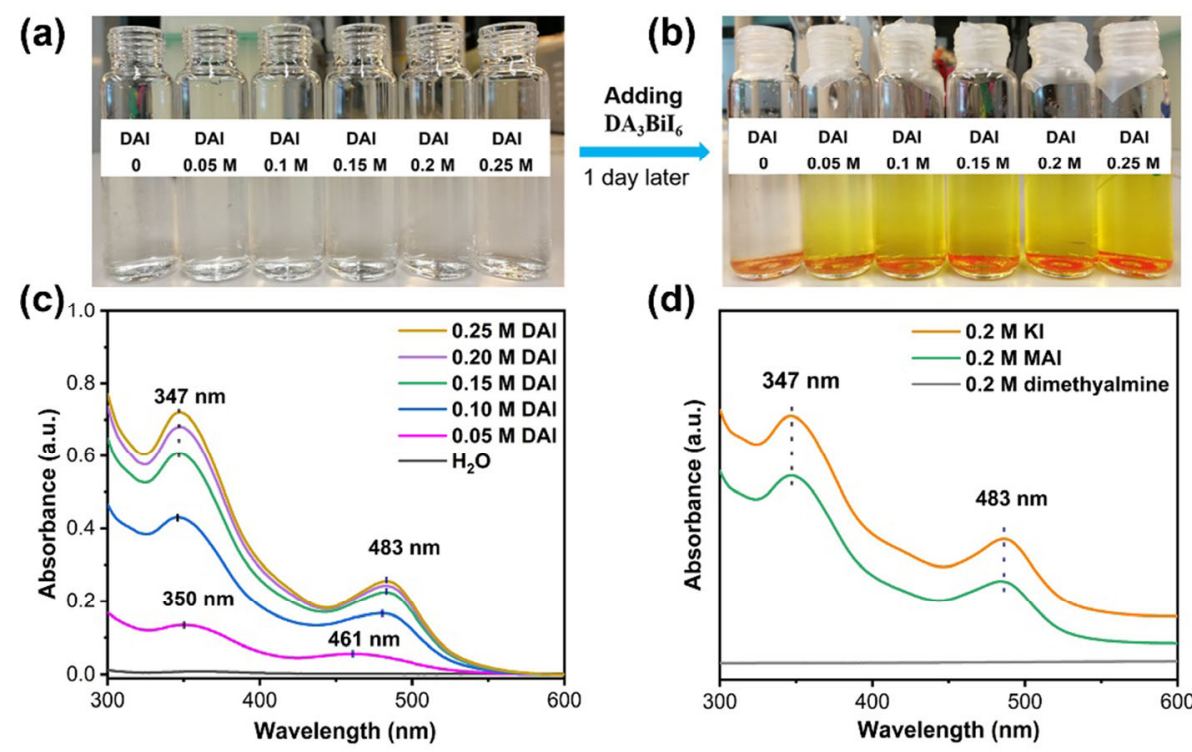

(d)

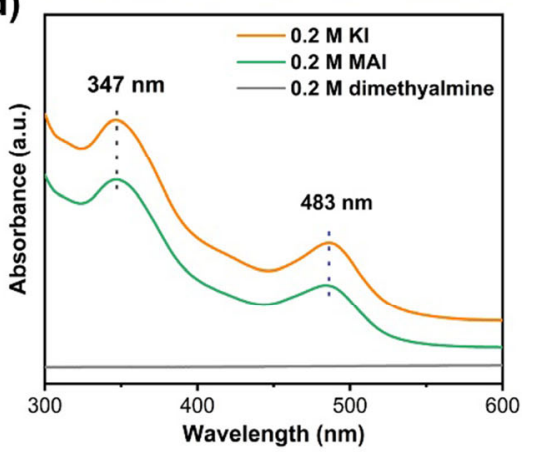

Figure 2 Stability of $\mathrm{DA}_{3} \mathrm{BiI}_{6}$ in aqueous DAI solution. Photographs of DAI solutions with different concentrations $(0,0.05,0.10,0.15,0.20$ and $0.25 \mathrm{M})$ before (a) and after (b) the addition of $\mathrm{DA}_{3} \mathrm{BiI}_{6}$ powder. (c) UV-vis spectra of solutions shown in (b) after 1 day of storage at room temperature. (d) UVvis spectra of $0.2 \mathrm{M}$ aqueous dimethylamine, $\mathrm{KI}$ and MAI solutions after immersing $\mathrm{DA}_{3} \mathrm{BiI}_{6}$ for $5 \mathrm{~min}$. 
could conclude that the $\mathrm{I}^{-}$ions from DAI can suppress the degradation of $\mathrm{DA}_{3} \mathrm{BiI}_{6}$ in water, without the use of encapsulation layers or the assistance of an acid.

Another aspect to be studied is related to the long-term stability of $\mathrm{DA}_{3} \mathrm{BiI}_{6}$ in DAI solution and the underlying reasons behind the stabilization. To examine the long-term stability, $\mathrm{DA}_{3} \mathrm{BiI}_{6}$ was mixed in $0.2 \mathrm{M}$ DAI solution (all experiments reported below are for $0.2 \mathrm{M}$ DAI solution unless otherwise stated) for two weeks, then the powder was collected (denoted as $\mathrm{I}_{-}-\mathrm{DA}_{3} \mathrm{BiI}_{6}$ ) for further analysis. First, the composition before and after immersion was investigated by using ATR-FTIR spectroscopy, as shown in Fig. 3(a). Before the immersion, the $\mathrm{DA}_{3} \mathrm{BiI}_{6}$ powder showed the representative absorption peaks as reported before (see details in Fig. S6 in the ESM) [23]. After two weeks, new peaks at around 3,500 and $3,145 \mathrm{~cm}^{-1}$ appeared, while all other absorption peak positions remained the same. The weak broad peak centred at $3,500 \mathrm{~cm}^{-1}$ is due to $\mathrm{O}-\mathrm{H}$ vibration of surface adsorbed water [50], whereas the doublet around $3,100 \mathrm{~cm}^{-1}$ can be assigned to the hydrogenbonded $\mathrm{N}-\mathrm{H}\left(3,145 \mathrm{~cm}^{-1}\right)$ and free $\mathrm{N}-\mathrm{H}$ stretching vibration $\left(3,093 \mathrm{~cm}^{-1}\right)[41,51]$. The adsorbed water does not cause the peak position shift of other absorption bands, especially $\mathrm{N}-\mathrm{H}$ vibration, which indicates that the water just adsorbed on the surface of $\mathrm{I}_{-} \mathrm{DA}_{3} \mathrm{BiI}_{6}$ without reaching deeper in the bulk of the particles [50].

We also noted that the color of $\mathrm{DA}_{3} \mathrm{BiI}_{6}$ powder changed after immersion from orange to red (inset of Fig. 3(a)). It is well known that surface structural change or phase transformation can result in color difference $[52,53]$. Due to the ionic character of hybrid perovskites, the ions from halide perovskites can dissolve in water and then recrystallize at room temperature because of the low formation energy. For instance, this approach has been exploited for the synthesis of $\mathrm{CsPbBr}_{3}$ nanosheets from $\mathrm{Cs}_{4} \mathrm{PbBr}_{6}$ nanocrystals by aqueous phase exfoliation method [54]. Accordingly, we suspect that the color change in our work may originate from the reconstruction (i.e. dissolution of surface ions and subsequent recrystallization with $\mathrm{I}^{-}$and $\mathrm{DA}^{+}$ions in solution) of the surface of $\mathrm{DA}_{3} \mathrm{BiI}_{6}$ when exposed to aqueous DAI. During this process, the morphology and also the phase may be altered due to the difference between dissolution and recrystallization rates leading to altered optical scattering properties and consequently to a change in the color [55]. To verify this hypothesis, FESEM images before and after immersion were analyzed to study the change of microstructure. As displayed in Fig. 3(b), the surface of $\mathrm{DA}_{3} \mathrm{BiI}_{6}$ particles is smooth, whereas $\mathrm{I}_{-} \mathrm{DA}_{3} \mathrm{BiI}_{6}$ exhibits a rough surface and some plate-like particles formed on those (Fig. 3(c)). The rough surface leads to more exposed $\mathrm{DA}_{3} \mathrm{BiI}_{6}$ molecules in $\mathrm{I}_{-} \mathrm{DA}_{3} \mathrm{BiI}_{6}$. This result corroborates the increased intensity of I-DA ${ }_{3} \mathrm{BiI}_{6}$ powder in ATR-FTIR spectrum (Fig. 3(a)).

Phase transformation may occur due to the different rate of dissolution and recrystallization upon surface $\mathrm{DA}_{3} \mathrm{BiI}_{6}$ molecules, thus forming plate-like particles. In addition, owing to the orderdisorder dynamics of the polar dimethylammonium cations, (a)

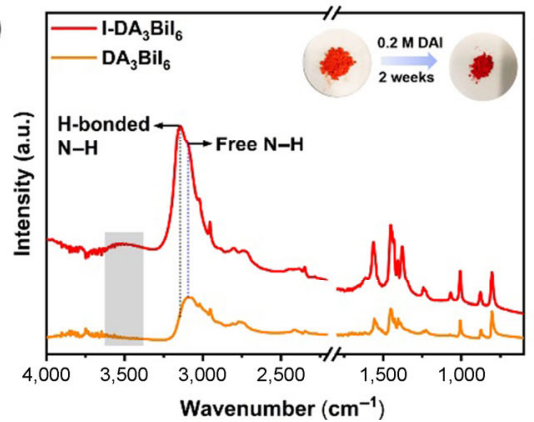

(c)

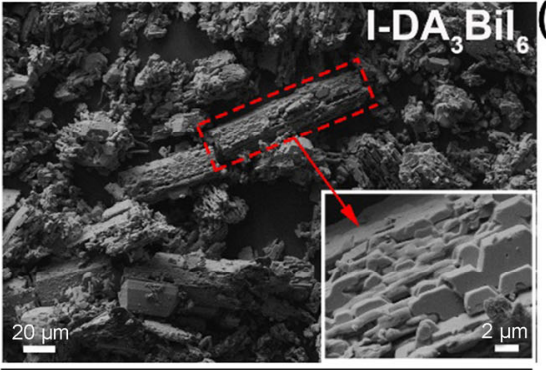

(e)

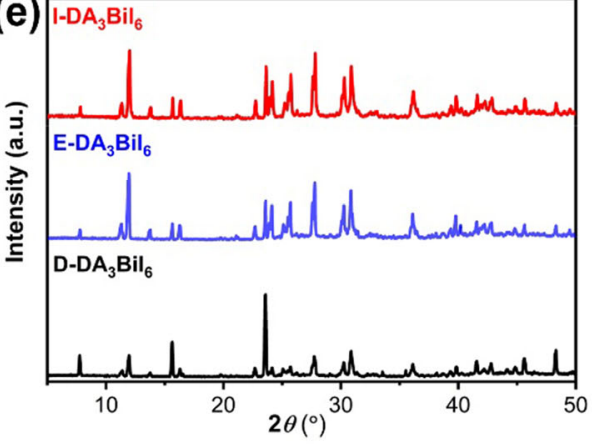

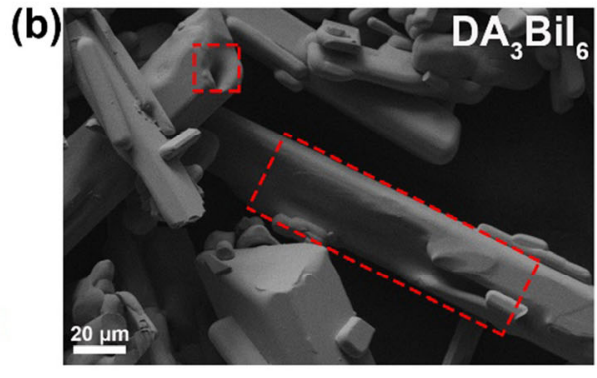

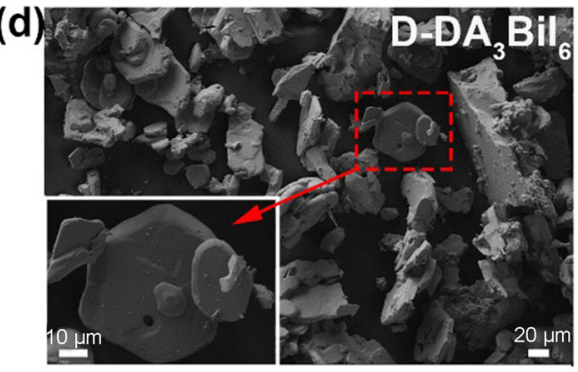

(f)

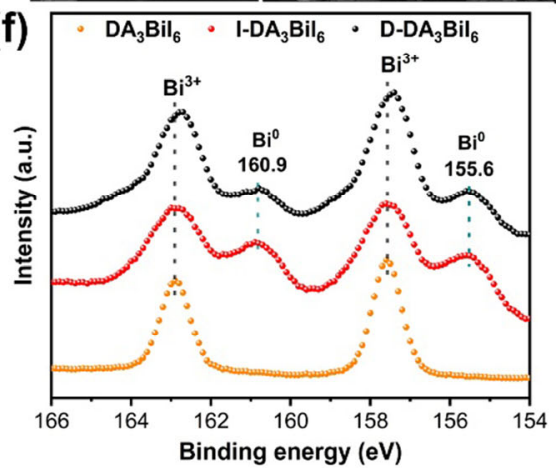

Figure 3 Phase transformation of $\mathrm{DA}_{3} \mathrm{BiI}_{6}$ powder in aqueous DAI solution. (a) ATR-FTIR spectra and color change of $\mathrm{DA}_{3} \mathrm{BiI}_{6}$ and $\mathrm{I}_{-} \mathrm{DA}_{3} \mathrm{BiI}_{6}$ powder (inset: color change before and after immersion). SEM images of (b) $\mathrm{DA}_{3} \mathrm{BiI}_{6}$, (c) $\mathrm{I}_{-} \mathrm{DA}_{3} \mathrm{BiI}_{6}$ and (d) D-DA $\mathrm{BiI}_{6}$. (e) XRD patterns of I-DA $\mathrm{XiI}_{6}, \mathrm{E}_{-} \mathrm{DA}_{3} \mathrm{BiI}_{6}$ and $\mathrm{D}-\mathrm{DA}_{3} \mathrm{BiI}_{6}$. (f) Resolved $\mathrm{Bi} 4 \mathrm{f}$ XPS peaks of $\mathrm{DA}_{3} \mathrm{BiI}_{6}, \mathrm{I}_{-}-\mathrm{DA}_{3} \mathrm{BiI}_{6}$ and $\mathrm{D}-\mathrm{DA}_{3} \mathrm{BiI}_{6}\left(\mathrm{I}_{-}-\mathrm{DA}_{3} \mathrm{BiI}_{6}\right.$ : $\mathrm{DA}_{3} \mathrm{BiI}_{6}$ powder was immersed in $\mathrm{DAI}$ solution for 2 weeks; D-DA ${ }_{3} \mathrm{BiI}_{6}$ : $\mathrm{DA}_{3} \mathrm{BiI}_{6}$ powder was prepared with $\mathrm{DAI}$; E-DA $\mathrm{DAiI}_{6}$ : $\mathrm{DA}_{3} \mathrm{BiI}_{6}$ powder was immersed in ethanol for 1 day). 
phase transformation is often observed in dimethylammonium metal hybrid compounds [56, 57]. In this work, during the cooling process, first the formation of small plate-like particles was observed, and then rod-like products were obtained after keeping the samples at ambient conditions overnight. In $\mathrm{DA}_{3} \mathrm{BiI}_{6}$, $\mathrm{DA}^{+}$ions are assumed to originate from the protonated dimethylamine after the hydrolysis of dimethylformamide (generating dimethylamine and formic acid) under acid conditions $[23,41]$. As described by Snaith et al., the remained formic acid in precursor solution can induce the oriented growth of crystal [58]. Therefore, $\mathrm{DA}_{3} \mathrm{BiI}_{6}$ powder using DAI instead of DMF (marked as $\mathrm{D}-\mathrm{DA}_{3} \mathrm{BiI}_{6}$ ) was tentatively prepared. As shown in Fig. 3(d), plate-like particles were obtained, similar to the newly formed particles in $\mathrm{I}_{-} \mathrm{DA}_{3} \mathrm{BiI}_{6}$. To confirm the phase, the XRD patterns of $\mathrm{I}_{-} \mathrm{DA}_{3} \mathrm{BiI}_{6}$ and $\mathrm{D}-\mathrm{DA}_{3} \mathrm{BiI}_{6}$ were assessed (Fig. 3(e)). While no significant differences in the $2 \theta$ positions were found, the relative intensities of the reflections were quite different. This was likely due to the different morphology of $\mathrm{I}_{-} \mathrm{DA}_{3} \mathrm{BiI}_{6}$ and $\mathrm{D}-\mathrm{DA}_{3} \mathrm{BiI}_{6}$ as shown in Figs. 3(c) and $3(\mathrm{~d})$. The $\mathrm{I}_{-} \mathrm{DA}_{3} \mathrm{BiI}_{6}$ powder still maintained the rod-like shape, which will influence the peak intensity of XRD patterns. Thus, ethanol was used to etch the surface of $\mathrm{DA}_{3} \mathrm{BiI}_{6}$ powder (denoted as $\mathrm{E}_{-} \mathrm{DA}_{3} \mathrm{BiI}_{6}$ ). Ethanol was chosen, since $\mathrm{DA}_{3} \mathrm{BiI}_{6}$ powder dissolves in ethanol slowly instead of complete dissolution immediately as occurs in other common polar solvents such as, dimethylformamide and acetonitrile. The XRD patterns from $\mathrm{I}_{-} \mathrm{DA}_{3} \mathrm{BiI}_{6}$ and $\mathrm{E}-\mathrm{DA}_{3} \mathrm{BiI}_{6}$ were further compared, and no indistinguishable change was observed. Thus, it is reasonable to conclude that the plate-like particles formed in $\mathrm{I}_{-} \mathrm{DA}_{3} \mathrm{BiI}_{6}$ originate from phase transformation of $\mathrm{DA}_{3} \mathrm{BiI}_{6}$ powder during the dissolution-recrystallization process. It is also worth mentioning, that common degradation products $\left(\mathrm{BiI}_{3}, \mathrm{BiOI}\right.$, DAI) were not found based on XRD (Fig. S7 in the ESM).

Furthermore, XPS analysis of the powders (Fig. 3(f)) indicates

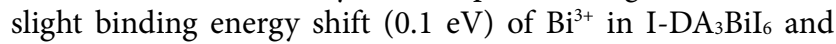
$\mathrm{D}-\mathrm{DA}_{3} \mathrm{BiI}_{6}$ as compared to $\mathrm{DA}_{3} \mathrm{BiI}_{6}$. This may be related to a small change of microenvironments caused by the recrystallization
[59]. The presence of $\mathrm{BiI}_{3}$ was further excluded due to the large difference in binding energy $\left(157.6 \mathrm{eV}\right.$ for $\mathrm{DA}_{3} \mathrm{BiI}_{6}$ versus $159.6 \mathrm{eV}$ for $\mathrm{BiI}_{3}$, Fig. S8 in the ESM). The additional peaks located at 155.6 and $160.9 \mathrm{eV}(\Delta=5.3 \mathrm{eV})$ can be assigned to metallic bismuth [60], originating from partial reduction of trivalent bismuth after exposure to X-ray. Similar behavior was often observed in other metal halide materials [61-63]. The above results demonstrated that the stability of $\mathrm{DA}_{3} \mathrm{BiI}_{6}$ powder in DAI solution originates from the phase transformation through a dissolution-recrystallization process of surface $\mathrm{DA}_{3} \mathrm{BiI}_{6}$ molecules.

\subsection{Photophysical and photocatalytic properties}

Prior to photocatalytic performance evaluation, the optical properties and electronic structure of $\mathrm{DA}_{3} \mathrm{BiI}_{6}$ were studied. As concluded from UV-vis absorption measurements, the $\mathrm{DA}_{3} \mathrm{BiI}_{6}$ powder absorbs wavelengths up to $\sim 570 \mathrm{~nm}$ (Fig. 4(a)). From the Tauc plot, the optical bandgap was determined to be $2.14 \mathrm{eV}$ (the inset in Fig. 4(a)) assuming indirect transitions (no good linearity was observed for direct band gap, as shown in Fig. S9 in the ESM). This claims that the $\mathrm{DA}_{3} \mathrm{BiI}_{6}$ is an indirect band gap material [64], which is consistent with our theorical result (Fig. 4(b)) from DFT calculations based on the reported crystal structure (hexagonal phase, Fig. S10 in the ESM) [23]. The valence band maximum (VBM) and conduction band maximum $(\mathrm{CBM})$ appear on $\mathrm{H}$ point and $\Gamma$ point respectively, proving an indirect band gap. The absolute band gap from calculations $(2.98 \mathrm{eV})$ compares reasonably well with the experimental data of $2.14 \mathrm{eV}$, if not considering the spin-orbit coupling effects in DFT calculations $[65,66]$. The carrier transport of $\mathrm{DA}_{3} \mathrm{BiI}_{6}$ was also predicted by calculating the reorganization energy based on Marcus theory [37, 38]. The smaller reorganization energy means the faster carrier transport. The calculated reorganization energy is $73 \mathrm{meV}$ for holes and $26 \mathrm{meV}$ for electrons, respectively. Both are smaller than the reported values of $\mathrm{MAPbI}_{3}(410 \mathrm{meV}$ for holes and $90 \mathrm{meV}$ for electrons) [39], suggesting that $\mathrm{DA}_{3} \mathrm{BiI}_{6}$ is preferred for efficient
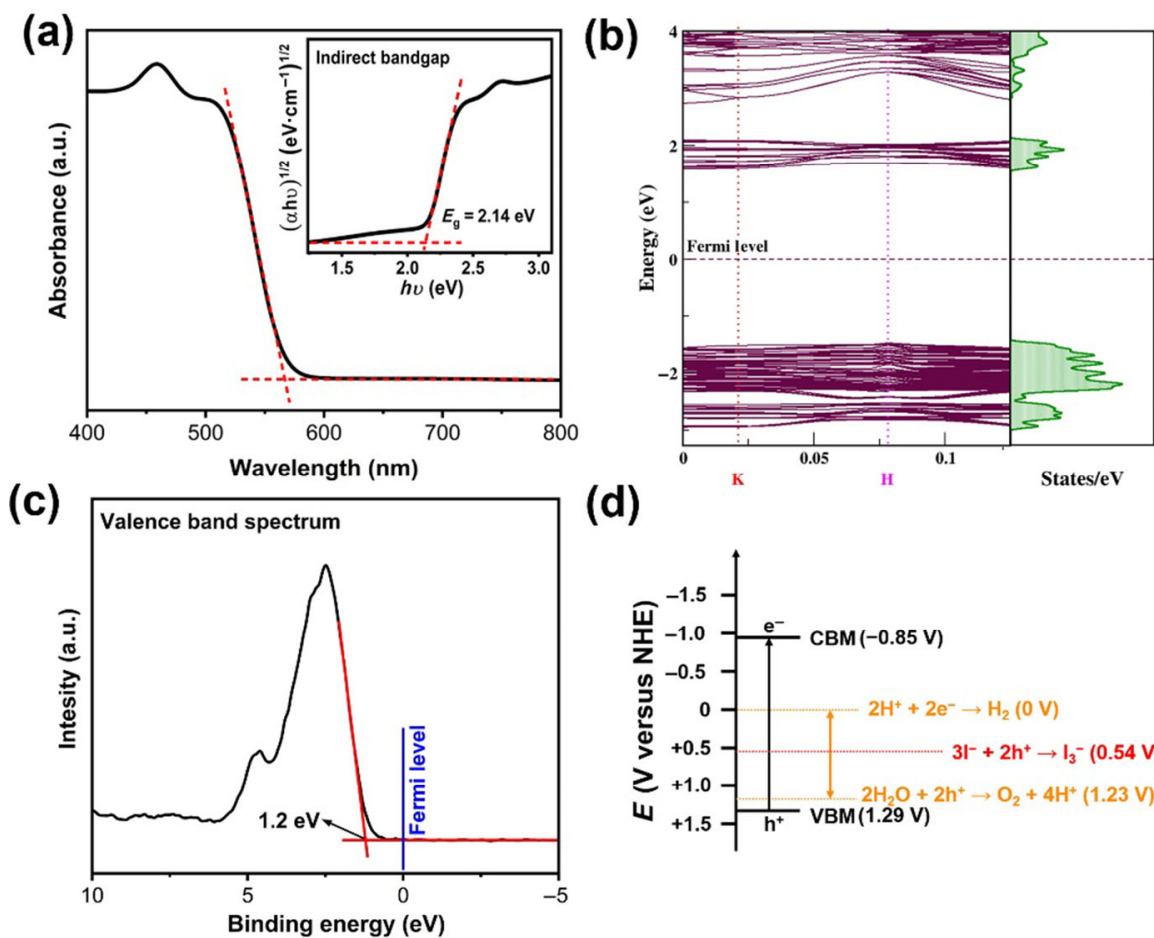

(d)

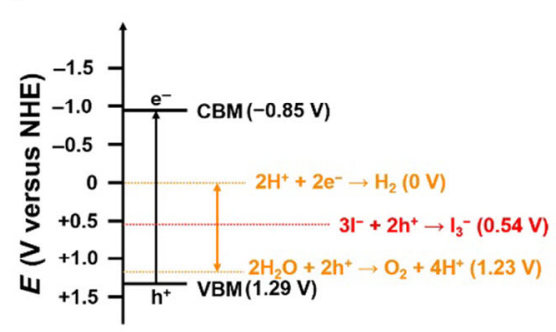

Figure 4 Band structure of $\mathrm{DA}_{3} \mathrm{BiI}_{6}$. (a) UV-vis absorption spectrum and Tauc plot of $\mathrm{DA}_{3} \mathrm{BiI}_{6}$ powder. (b) Electronic band structure and corresponding projected density of states of $\mathrm{DA}_{3} \mathrm{BiI}_{6}$. (c) Valence level spectrum of $\mathrm{DA}_{3} \mathrm{BiI}_{6}$ powder measured by XPS. (d) Schematic band diagrams of $\mathrm{DA}_{3} \mathrm{BiI}_{6} \mathrm{Powder}$ and the redox potentials for water splitting and $\mathrm{I}^{-}$ions oxidation reaction. 
transportation of the carrier, and holds the promise for better photocatalytic property than the lead analogs. The electronic structure was further elucidated from valence-band XPS spectrum (Fig. 4(c)) showing the VBM position of $\mathrm{DA}_{3} \mathrm{BiI}_{6}$ to be located at $1.2 \mathrm{eV}$ versus Fermi level. Now, by considering the optical bandgap, the CBM is at $-3.61 \mathrm{eV}$ [67]. Thus, the $\mathrm{CBM}$ and $\mathrm{VBM}$ of $\mathrm{DA}_{3} \mathrm{BiI}_{6}$ are located at -0.85 and $1.29 \mathrm{~V}$ with respect to the normal hydrogen electrode (NHE) [68]. Note that the CBM of $\mathrm{DA}_{3} \mathrm{BiI}_{6}$ is at a more negative potential than the potential of proton reduction (Fig. 4(d)), which indicates that the photo-generated electrons would have sufficient driving forces to reduce proton and generate $\mathrm{H}_{2}$. However, since the VBM is more positive than the potential of iodine oxidation as compared to that of water oxidation, the photo-generated holes from $\mathrm{DA}_{3} \mathrm{BiI}_{6}$ prefer to oxidize $\mathrm{I}^{-}$ions to $\mathrm{I}_{3}^{-}$ions instead of oxidizing water to oxygen or $\mathrm{I}^{-}$ions to $\mathrm{IO}_{3}^{-}$ions [69].

The possibility of photocatalytic $\mathrm{H}_{2}$ evolution in DAI solution was firstly evaluated using a commercial LED as light source (100 W, photocatalytic system and light spectrum shown in the inset of Fig. 5(a) and Fig. S11 in the ESM, respectively). Although no $\mathrm{H}_{2}$ signal was detected after $24 \mathrm{~h}$, we noted that the $\mathrm{I}^{-}$ions were oxidized to $\mathrm{I}_{3}{ }^{-}$ions (Fig. $\mathrm{S} 12$ in the ESM) and the concentration of $\mathrm{I}_{3}^{-}$ions was determined to be 142, 268, and $339 \mu \mathrm{mol} \cdot \mathrm{L}^{-1}$ at $4,8,12 \mathrm{~h}$, respectively (Fig. S13 in the ESM and Fig. 5(a)), demonstrating photocatalytic reactions occur on $\mathrm{DA}_{3} \mathrm{BiI}_{6}$ under LED irradiation. Since small amount of $\mathrm{I}_{3}{ }^{-}$ions were produced after $12 \mathrm{~h}$ without $\mathrm{DA}_{3} \mathrm{BiI}_{6}$, the generated $\mathrm{I}_{3}{ }^{-}$ ions are supposed to be mainly from photocatalytic reactions of $\mathrm{DA}_{3} \mathrm{BiI}_{6}$ powder in this system.

Although it was demonstrated that photooxidation reaction can be realized on $\mathrm{DA}_{3} \mathrm{BiI}_{6}$ in acid-free aqueous solution under visible light irradiation for the first time, the photocatalytic activity is still not adequate for $\mathrm{H}_{2}$ evolution. This possibly originates from the relatively high overpotential for water splitting, which requires four electrons, while only two electrons are needed for acid-splitting [70]. Therefore, photocatalytic $\mathrm{H}_{2}$ generation with $\mathrm{DA}_{3} \mathrm{BiI}_{6}$ in the presence of aqueous $\mathrm{HI}$ solution was examined. In this study, $\mathrm{H}_{3} \mathrm{PO}_{2}$ was added to alleviate the effect of evolved $\mathrm{I}_{3}{ }^{-}$ions [11], and a series of HI solutions (namely, 1.52, 2.28, 3.04 and 3.8 M) were prepared by adjusting the amount of DAI solution. To optimize the photocatalytic efficiency, $\mathrm{PtCl}_{4}$ powder $(1 \mathrm{mg})$ was added simultaneously as a co-catalyst (denoted as $\mathrm{Pt}-\mathrm{DA}_{3} \mathrm{BiI}_{6}$ ) [23]. The hydrogen gas was measured with a micro gas chromatography. In the first place, the solubility of $\mathrm{DA}_{3} \mathrm{BiI}_{6}$ powder in HI solution was determined to be about $133 \mathrm{mg} \cdot \mathrm{mL}^{-1}$ (Table S1 in the ESM), indicating forming of a homogeneous solution for all the evaluated cases. As displayed in Fig. 5(b), all examined cases showed photocatalytic $\mathrm{H}_{2}$ evolution activity under visible light irradiation suggesting the possibility of photocatalytic HI-splitting activity for $\mathrm{DA}_{3} \mathrm{BiI}_{6}$ powders in aqueous DAI solution. In particular, the amount of $\mathrm{H}_{2}$ evolution increased to the optimal value of $4.25 \mu \mathrm{mol}$ for $3.04 \mathrm{M}$ of HI solution after $1 \mathrm{~h}$ irradiation. Control experiments demonstrated that no $\mathrm{H}_{2}$ signals were detected in the absence of light or the photocatalyst, which means that $\mathrm{H}_{2}$ was formed via the photocatalytic reaction. The amount of $\mathrm{DA}_{3} \mathrm{BiI}_{6}$ on photocatalytic activity was also studied as shown in Fig. S14 in the ESM. The best hydrogen evolution activity was $4.55 \mu \mathrm{mol}$ after $1 \mathrm{~h}$ reaction when $50 \mathrm{mg}$ of $\mathrm{DA}_{3} \mathrm{BiI}_{6}$ was used. Moreover, $\mathrm{Pt}-\mathrm{DA}_{3} \mathrm{BiI}_{6}$ showed good structural stability assessed by XRD (Fig. S15 in the ESM) and retained its photocatalytic activity for $\mathrm{H}_{2}$ evolution in repeated experiments with an average evolution rate of $5.7 \mu \mathrm{mol} \cdot \mathrm{h}^{-1}$ (Fig. 5(c)). The apparent quantum efficiency was determined by applying monochromatic LED lamp (Fig. 5(d)). As shown in Fig. S16 in the ESM, the reaction solution absorbs all the light up to $520 \mathrm{~nm}$, thus assuming that the total power was utilized by the photocatalyst. The $\mathrm{H}_{2}$ evolution rate $\left(\mu \mathrm{mol} \cdot \mathrm{h}^{-1}\right)$ surpasses some reported data over $\mathrm{Pt}-\mathrm{MAPbX}_{3}(\mathrm{X}=\mathrm{I}, \mathrm{Br})$ or $\mathrm{Pt}-\mathrm{Cs}_{2} \mathrm{AgBiBr}_{6}$ for $\mathrm{H}_{2}$ evolution from concentrated $\mathrm{HI}$ solution (Fig. 5(e)) $[12,13,15,19]$. The smaller calculated reorganization energy as described above and the homogeneous system applied instead of heterogeneous system may contribute to the better performance [23,39]. Figure 5(f) shows the AQE values of $\mathrm{Pt}_{-} \mathrm{DA}_{3} \mathrm{BiI}_{6}$ in $3.04 \mathrm{M}$ of HI solution under different (a)

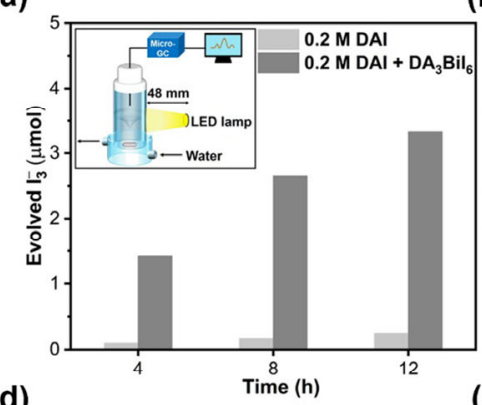

(d)

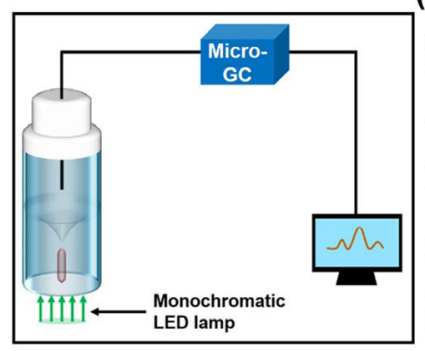

(b)

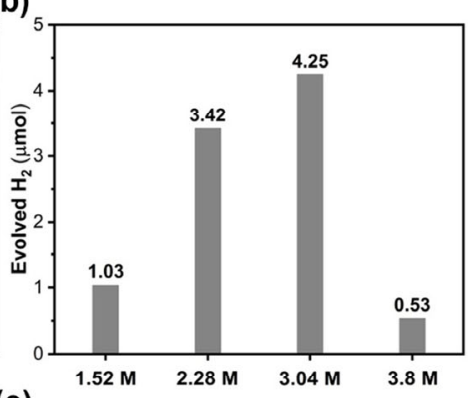

(e)

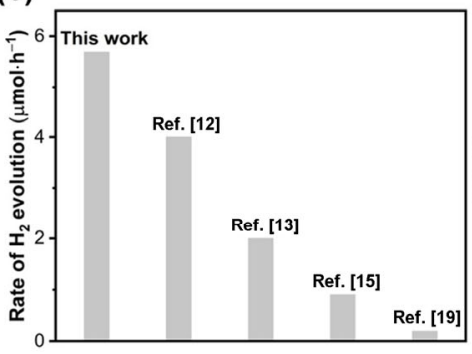

(c)

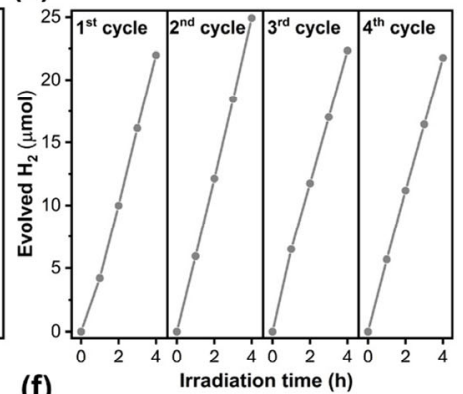

(f)

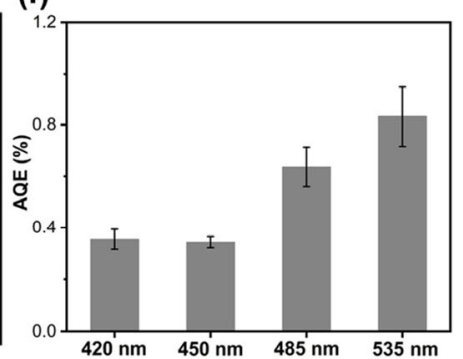

Figure 5 Photocatalytic performance of $\mathrm{DA}_{3} \mathrm{BiI}_{6}$ photocatalysts. (a) Evolved $\mathrm{I}_{3}{ }^{-}$ions in $0.2 \mathrm{M}$ DAI solution without and with $\mathrm{DA}_{3} \mathrm{BiI}_{6}$ powder under white LED irradiation (inset: schematic illustration of side irradiation for the evaluated activities shown in (a)-(c)). (b) The photocatalytic $\mathrm{H}_{2}$ evolution activities on $\mathrm{Pt}_{-} \mathrm{DA}_{3} \mathrm{BiI}_{6}$ with different concentration of $\mathrm{HI}\left(100 \mathrm{mg}\right.$ of $\mathrm{DA}_{3} \mathrm{BiI}_{6}, 1 \mathrm{~h}$ ). (c) Cycling runs of the $\mathrm{Pt}_{-} \mathrm{DA} \mathrm{BiI}_{6}$ for photocatalytic $\mathrm{H}_{2}$ evolution (3.04 M of HI, $50 \mathrm{mg}$ of $\mathrm{DA}_{3} \mathrm{BiI}_{6}$ ). (d) Schematic diagram of the setup used for AQE measurements. (e) Comparison of photocatalytic $\mathrm{H}_{2}$ evolution rates between this work and reported Pt-decorated halide perovskite systems. (f) AQE values of $\mathrm{H}_{2}$ evolution over Pt-DA3 BiI in $3.04 \mathrm{M}$ of $\mathrm{HI}$ solution under different wavelength, the error bar represents the SD of the measurements. 
monochromatic LED irradiation and the AQE values were $0.35 \%, 0.34 \%, 0.64 \%$ and $0.83 \%$ at $420,450,485$ and $535 \mathrm{~nm}$, respectively, indicating that this photocatalyst can work from the wavelength of $420 \mathrm{~nm}$ up to $535 \mathrm{~nm}$. Though the performance is still low, the AQE values exceed the reported data $(0.16 \%$ at $450 \mathrm{~nm})$ of double perovskite $\mathrm{Cs}_{2} \mathrm{AgBiBr}_{6} / \mathrm{RGO}$ for $\mathrm{H}_{2}$ evolution from $\mathrm{HBr}$-splitting (Fig. 5(d)). Note that as a co-catalyst, the reduced graphene oxide (RGO) displayed ca. 51 times and ca. 23 times higher photocatalytic $\mathrm{H}_{2}$ generation rate than $\mathrm{Pt}$ in $\mathrm{Cs}_{2} \mathrm{AgBiBr}_{6}$ and $\mathrm{CH}_{3} \mathrm{NH}_{3} \mathrm{PbI}_{3}$, respectively $[12,19]$. More importantly, the $\mathrm{DA}_{3} \mathrm{BiI}_{6}$ demonstrates hightolerance to water. So, we believe that there is great space to optimze its photocatalytic activity in low concentration of halogen acid solutions or pure water via electronic structure engineering or heterojunction engineering [71].

\section{Conclusions}

In summary, a lead-free bismuth halide perovskite $\mathrm{DA}_{3} \mathrm{BiI}_{6}$ was synthesized and stabilized in aqueous DAI solution over 2 weeks without the addition of acids. The $\mathrm{I}^{-}$ions from DAI molecules in aqueous solution can alleviate the degradation and thus stabilize the $\mathrm{DA}_{3} \mathrm{BiI}_{6}$ powder through a surface dissolution-recrystallization process when the concentration of DAI solution is higher than $0.15 \mathrm{M}$. The photophysical properties of $\mathrm{DA}_{3} \mathrm{BiI}_{6}$ were thoroughly studied by experimental and modelling approaches proving that $\mathrm{DA}_{3} \mathrm{BiI}_{6}$ as a photocatalyst is suitable for hydrogen evolution. As a proof of concept, $\mathrm{DA}_{3} \mathrm{BiI}_{6}$ was applied as a photocatalyst for photooxidation of $\mathrm{I}^{-}$ions as well as photocatalytic hydrogen evolution from $\mathrm{HI}$ in DAI solutions for the first time. Using $\mathrm{PtCl}_{4}$ as a co-catalyst. a $\mathrm{H}_{2}$ evolution rate of $5.7 \mu \mathrm{mol} \cdot \mathrm{h}^{-1}$ during 4 runs with no significant decrease in activity was obtained, yielding an AQE of $0.83 \%$ at $535 \mathrm{~nm}$. The bismuth-based perovskite developed in this work exhibits high-tolerance to water and can broaden the applications of halide hybrid perovskite family in photocatalytic systems.

\section{Acknowledgements}

This work was supported by the Kvantum Institute Emerging Project at the University of Oulu and Academy of Finland ELECTRA-project (No. 2430291511). We thank Raija Oilunkaniemi and Markus Riihimäki for the help with XRD and ATR characterization, respectively. We are grateful to the staff from Centre for Material Analysis (University of Oulu) for the characterization. ELI-ALPS is supported by the European Union and co-financed by the European Regional Development Fund (No. GINOP-2.3.6-15-2015-00001). M. U. K. also acknowledges funding from PaNOSC European project.

Funding note: Open access funding provided by University of Oulu including Oulu University Hospital.

Electronic Supplementary Material: Supplementary material (additional supporting figures EDS, XRD, UV-vis spectra, ATRFTIR, XPS, crystal structure of $\mathrm{DA}_{3} \mathrm{BiI}_{6}$ and photocatalytic $\mathrm{H}_{2}$ evolution activities) is available in the online version of this article at https://doi.org/10.1007/s12274-020-3159-0.

Open Access This article is licensed under a Creative Commons Attribution 4.0 International License, which permits use, sharing, adaptation, distribution and reproduction in any medium or format, as long as you give appropriate credit to the original author(s) and the source, provide a link to the Creative Commons licence, and indicate if changes were made.

The images or other third party material in this article are included in the article's Creative Commons licence, unless indicated otherwise in a credit line to the material. If material is not included in the article's Creative Commons licence and your intended use is not permitted by statutory regulation or exceeds the permitted use, you will need to obtain permission directly from the copyright holder.

To view a copy of this licence, visit http://creativecommons.org/licenses/by/4.0/

\section{References}

[1] Fujishima, A.; Honda, K. Electrochemical photolysis of water at a semiconductor electrode. Nature 1972, 238, 37-38.

[2] Wang, Q.; Domen, K. Particulate photocatalysts for light-driven water splitting: Mechanisms, challenges, and design strategies. Chem. Rev. 2020, 120, 919-985.

[3] Heyduk, A. F.; Nocera, D. G. Hydrogen produced from hydrohalic acid solutions by a two-electron mixed-valence photocatalyst. Science 2001, 293, 1639-1641.

[4] Osterloh, F. E. Inorganic materials as catalysts for photochemical splitting of water. Chem. Mater. 2008, 20, 35-54.

[5] Schneider, J.; Matsuoka, M.; Takeuchi, M.; Zhang, J. L.; Horiuchi, Y.; Anpo, M.; Bahnemann, D. W. Understanding $\mathrm{TiO}_{2}$ photocatalysis: Mechanisms and materials. Chem. Rev. 2014, 114, 9919-9986.

[6] Kojima, A.; Teshima, K.; Shirai, Y.; Miyasaka, T. Organometal halide perovskites as visible-light sensitizers for photovoltaic cells. J. Am. Chem. Soc. 2009, 131, 6050-6051.

[7] Chen, B.; Baek, S. W.; Hou, Y.; Aydin, E.; De Bastiani, M.; Scheffel, B.; Proppe, A.; Huang, Z. R.; Wei, M. Y; Wang, Y. K. et al. Enhanced optical path and electron diffusion length enable high-efficiency perovskite tandems. Nat. Commun. 2020, 11, 1257.

[8] Chen, Q.; De Marco, N.; Yang, Y.; Song, T. B.; Chen, C. C.; Zhao, H. X.; Hong, Z. R.; Zhou, H. P.; Yang, Y. Under the spotlight: The organic-inorganic hybrid halide perovskite for optoelectronic applications. Nano Today 2015, 10, 355-396.

[9] Xing, G. C.; Mathews, N.; Sun, S. Y.; Lim, S. S.; Lam, Y. M.; Grätzel, M.; Mhaisalkar, S.; Sum, T. C. Long-range balanced electron- and hole-transport lengths in organic-inorganic $\mathrm{CH}_{3} \mathrm{NH}_{3} \mathrm{PbI}_{3}$. Science 2013, 342, 344-347.

[10] Dong, Q. F.; Fang, Y. J.; Shao, Y. C.; Mulligan, P.; Qiu, J.; Cao, L.; Huang, J. S. Electron-hole diffusion lengths $>175 \mu \mathrm{m}$ in solutiongrown $\mathrm{CH}_{3} \mathrm{NH}_{3} \mathrm{PbI}_{3}$ single crystals. Science 2015, 347, 967-970.

[11] Park, S.; Chang, W. J.; Lee, C. W.; Park, S.; Ahn, H. Y.; Nam, K. T. Photocatalytic hydrogen generation from hydriodic acid using methylammonium lead iodide in dynamic equilibrium with aqueous solution. Nat. Energy 2017, 2, 16185.

[12] Wu, Y. Q.; Wang, P.; Zhu, X. L.; Zhang, Q. Q.; Wang, Z. Y.; Liu, Y. Y.; Zou, G. Z.; Dai, Y.; Whangbo, M. H.; Huang, B. B. Composite of $\mathrm{CH}_{3} \mathrm{NH}_{3} \mathrm{PbI}_{3}$ with reduced graphene oxide as a highly efficient and stable visible-light photocatalyst for hydrogen evolution in aqueous HI solution. Adv. Mater. 2018, 30, 1704342 .

[13] Wang, H.; Wang, X. M.; Chen, R. T.; Zhang, H. F.; Wang, X. L.; Wang, J. H.; Zhang, J.; Mu, L. C.; Wu, K. F.; Fan, F. T. et al. Promoting photocatalytic $\mathrm{H}_{2}$ evolution on organic-inorganic hybrid perovskite nanocrystals by simultaneous dual-charge transportation modulation. ACS Energy Lett. 2019, 4, 40-47.

[14] Zhao, Z. J.; Wu, J. J.; Zheng, Y. Z.; Li, N.; Li, X. T.; Tao, X. Ni ${ }_{3} \mathrm{C}-$ decorated $\mathrm{MAPbI}_{3}$ as visible-light photocatalyst for $\mathrm{H}_{2}$ evolution from HI splitting. ACS Catal. 2019, 9, 8144-8152.

[15] Wang, X. M.; Wang, H.; Zhang, H. F.; Yu, W.; Wang, X. L.; Zhao, Y.; Zong, X.; Li, C. Dynamic interaction between methylammonium lead iodide and $\mathrm{TiO}_{2}$ nanocrystals leads to enhanced photocatalytic $\mathrm{H}_{2}$ evolution from HI splitting. ACS Energy Lett. 2018, 3, 1159-1164.

[16] Guan, Z. H.; Wu, Y. Q.; Wang, P.; Zhang, Q. Q.; Wang, Z. Y.; Zheng, Z. K.; Liu, Y. Y.; Dai, Y.; Whangbo, M. H.; Huang, B. B. Perovskite photocatalyst $\mathrm{CsPbr}_{3-x} \mathrm{I}_{x}$ with a bandgap funnel structure for $\mathrm{H}_{2}$ evolution under visible light. Appl. Catal. B Environ. 2019, $245,522-527$.

[17] Wang, M. Y.; Zuo, Y. P.; Wang, J. L.; Wang, Y.; Shen, X. P.; Qiu, B. C.; Cai, L. J.; Zhou, F. C.; Lau, S. P.; Chai, Y. Remarkably enhanced hydrogen generation of organolead halide perovskites via piezocatalysis and photocatalysis. Adv. Energy Mater. 2019, 9, 1901801. 
[18] Wu, Y. Q.; Wang, P.; Guan, Z. H.; Liu, J. X.; Wang, Z. Y.; Zheng, Z. K.; Jin, S. Y.; Dai, Y.; Whangbo, M. H.; Huang, B. B. Enhancing the photocatalytic hydrogen evolution activity of mixed-halide perovskite $\mathrm{CH}_{3} \mathrm{NH}_{3} \mathrm{PbBr}_{3-x} \mathrm{I}_{x}$ achieved by bandgap funneling of charge carriers. ACS Catal. 2018, 8, 10349-10357.

[19] Wang, T.; Yue, D. T.; Li, X.; Zhao, Y. X. Lead-free double perovskite $\mathrm{Cs}_{2} \mathrm{AgBiBr}_{6} / \mathrm{RGO}$ composite for efficient visible light photocatalytic $\mathrm{H}_{2}$ evolution. Appl. Catal. B Environ. 2020, 268, 118399.

[20] Vesborg, P. C. K. Photocatalysis: HI-time for perovskites. Nat. Energy 2017, 2, 16205.

[21] Li, J. M.; Cao, H. L.; Jiao, W. B.; Wang, Q.; Wei, M. D.; Cantone, I.; Lü, J.; Abate, A. Biological impact of lead from halide perovskites reveals the risk of introducing a safe threshold. Nat. Commun. 2020, 11,310 .

[22] Zhang, L.; Wang, K.; Zou, B. Bismuth halide perovskite-like materials: Current opportunities and challenges. ChemSusChem 2019, 12, 16121630.

[23] Zhao, H.; Li, Y. X.; Zhang, B.; Xu, T.; Wang, C. Y. Ptt $x_{x} /$ $\left[\left(\mathrm{CH}_{3}\right)_{2} \mathrm{NH}_{2}\right]_{3}\left[\mathrm{BiI}_{6}\right]$ as a well-dispersed photocatalyst for hydrogen production in hydroiodic acid. Nano Energy 2018, 50, 665-674.

[24] Chu, K. B.; Xie, J. L.; Chen, W. J.; Lu, W. X.; Song, J. L.; Zhang, C. A novel bismuth-based hybrid material with highly activity for fast removal of rhodamine B under dark conditions. Polyhedron 2018, $151,146-151$.

[25] Liu, H.; Siron, M.; Gao, M. Y.; Lu, D.; Bekenstein, Y.; Zhang, D. D.; Dou, L. T.; Alivisatos, A. P.; Yang, P. D. Lead halide perovskite nanowires stabilized by block copolymers for Langmuir-Blodgett assembly. Nano Res. 2020, 13, 1453-1458.

[26] Poli, I.; Hintermair, U.; Regue, M.; Kumar, S.; Sackville, E. V.; Baker, J.; Watson, T. M.; Eslava, S.; Cameron, P. J. Graphite-protected $\mathrm{CsPbr}_{3}$ perovskite photoanodes functionalised with water oxidation catalyst for oxygen evolution in water. Nat. Commun. 2019, 10, 2097.

[27] Hu, S.; Shaner, M. R.; Beardslee, J. A.; Lichterman, M.; Brunschwig, B. S.; Lewis, N. S. Amorphous $\mathrm{TiO}_{2}$ coatings stabilize Si, GaAs, and GaP photoanodes for efficient water oxidation. Science 2014, 344, 1005-1009.

[28] Wang, H.; Wang, X. M.; Zhang, H. F.; Ma, W. G.; Wang, L. Z.; Zong, X. Organic-inorganic hybrid perovskites: Game-changing candidates for solar fuel production. Nano Energy 2020, 71, 104647.

[29] Ke, W. J.; Spanopoulos, I.; Stoumpos, C. C.; Kanatzidis, M. G. Myths and reality of $\mathrm{HPbI}_{3}$ in halide perovskite solar cells. Nat. Commun. 2018, 9, 4785 .

[30] Meng, H. G.; Shao, Z. P.; Wang, L.; Li, Z. P.; Liu, R. R.; Fan, Y. P.; Cui, G. L.; Pang, S. P. Chemical composition and phase evolution in DMAI-derived inorganic perovskite solar cells. ACS Energy Lett. 2020, 5, 263-270.

[31] Pisanu, A.; Speltini, A.; Quadrelli, P.; Drera, G.; Sangaletti, L.; Malavasi, L. Enhanced air-stability of Sn-based hybrid perovskites induced by dimethylammonium (DMA): Synthesis, characterization, aging and hydrogen photogeneration of the $\mathrm{MA}_{1-X} \mathrm{DMA}_{X} \mathrm{SnBr}_{3}$ system. J. Mater. Chem. C 2019, 7, 7020-7026.

[32] Eperon, G. E.; Stone, K. H.; Mundt, L. E.; Schloemer, T. H.; Habisreutinger, S. N.; Dunfield, S. P.; Schelhas, L. T.; Berry, J. J.; Moore, D. T. The role of dimethylammonium in bandgap modulation for stable halide perovskites. ACS Energy Lett. 2020, 5, 1856-1864.

[33] Bian, H.; Wang, H. R.; Li, Z. Z.; Zhou, F. G.; Xu, Y. K.; Zhang, H.; Wang, Q.; Ding, L. M.; Liu, S. Z.; Jin, Z. W. Unveiling the effects of hydrolysis-derived $\mathrm{DMAI} / \mathrm{DMAPbI}_{X}$ intermediate compound on the performance of $\mathrm{CsPbI}_{3}$ solar cells. Adv. Sci. 2020, 7, 1902868.

[34] Xiao, M.; Hao, M. M.; Lyu, M. Q.; Moore, E. G.; Zhang, C.; Luo, B.; Hou, J. W.; Lipton-Duffin, J.; Wang, L. Z. Surface ligands stabilized lead halide perovskite quantum dot photocatalyst for visible lightdriven hydrogen generation. Adv. Funct. Mater. 2019, 29, 1905683.

[35] Mu, Y. F.; Zhang, W.; Guo, X. X.; Dong, G. X.; Zhang, M.; Lu, T. B. Water-tolerant lead halide perovskite nanocrystals as efficient photocatalysts for visible-light-driven $\mathrm{CO}_{2}$ reduction in pure water. ChemSusChem 2019, 12, 4769-4774.

[36] Giannozzi, P.; Andreussi, O.; Brumme, T.; Bunau, O.; Nardelli, M. B.; Calandra, M.; Car, R.; Cavazzoni, C.; Ceresoli, D.; Cococcioni, M. et al. Advanced capabilities for materials modelling with Quantum ESPRESSO. J. Phys. Condens. Matter. 2017, 29, 465901.
[37] Marcus, R. A. On the theory of oxidation-reduction reactions involving electron transfer. I. J. Chem. Phys. 1956, 24, 966-978.

[38] Marcus, R. A. Transfer reactions in chemistry. Theory and experiment. Pure Appl. Chem. 1997, 69, 13-30.

[39] Meng, G. H.; Feng, Y. P.; Song, X. D.; Shi, Y. T.; Ji, M.; Xue, Y.; Hao, C. Theoretical insight into the carrier mobility anisotropy of organic-inorganic perovskite $\mathrm{CH}_{3} \mathrm{NH}_{3} \mathrm{PbI}_{3}$. J. Electroanal. Chem. 2018, 810, 11-17.

[40] Tang, Y. Q.; Mak, C. H.; Liu, R. G.; Wang, Z. K.; Ji, L.; Song, H. S.; Tan, C. Y.; Barrière, F.; Hsu, H. Y. In situ formation of bismuth-based perovskite heterostructures for high-performance cocatalyst-free photocatalytic hydrogen evolution. Adv. Funct. Mater., in press, DOI: 10.1002/adfm.202006919.

[41] Samet, A.; Ahmed, A. B.; Mlayah, A.; Boughzala, H.; Hlil, E. K.; Abid, Y. Optical properties and ab initio study on the hybrid organicinorganic material $\left[\left(\mathrm{CH}_{3}\right)_{2} \mathrm{NH}_{2}\right]_{3}\left[\mathrm{BiI}_{6}\right]$. J. Mol. Struct. 2010, 977, $72-77$.

[42] Ingo, G. M.; Paparazzo, E.; Bagnarelli, O.; Zacchetti, N. XPS studies on cerium, zirconium and yttrium valence states in plasmasprayed coatings. Surf. Interface Anal. 1990, 16, 515-519.

[43] Lee, W. W.; Lu, C. S.; Chuang, C. W.; Chen, Y. J.; Fu, J. Y.; Siao, C. W.; Chen, C. C. Synthesis of bismuth oxyiodides and their composites: Characterization, photocatalytic activity, and degradation mechanisms. RSC Adv. 2015, 5, 23450-23463.

[44] Zheng, C.; Rubel, O. Unraveling the water degradation mechanism of $\mathrm{CH}_{3} \mathrm{NH}_{3} \mathrm{PbI}_{3}$. J. Phys. Chem. C 2019, 123, 19385-19394.

[45] Zhao, Q.; Peng, Y.; Huang, Z. X.; Liu, C.; Zhou, P.; Li, W. N.; Wang, S.; Cheng, Y. B. Recovering $\mathrm{MAPbI}_{3}$-based perovskite films from water-caused permanent degradations by dipping in MAI solution. IEEE J. Photovolt. 2018, 8, 1692-1700.

[46] Seth, C.; Khushalani, D. Degradation and regeneration of hybrid perovskites. RSC Adv. 2016, 6, 101846-101852.

[47] Horváth, O.; Mikó, I. Spectra, equilibrium and photoredox chemistry of iodobismuthate(III) complexes in acetonitrile. Inorganica Chim. Acta. 2000, 304, 210-218.

[48] Maurer, A. B.; Hu, K.; Meyer, G. J. Light excitation of a bismuth iodide complex initiates I-I bond formation reactions of relevance to solar energy conversion. J. Am. Chem. Soc. 2017, 139, 8066-8069.

[49] Nikol, H.; Vogler, A. Photoluminescence of antimony(III) and bismuth(III) chloride complexes in solution. J. Am. Chem. Soc. 1991, 113, 8988-8990.

[50] Müller, C.; Glaser, T.; Plogmeyer, M.; Sendner, M.; Döring, S.; Bakulin, A. A.; Brzuska, C.; Scheer, R.; Pshenichnikov, M. S.; Kowalsky, W. et al. Water infiltration in methylammonium lead iodide perovskite: Fast and inconspicuous. Chem. Mater. 2015, 27, 7835-7841.

[51] Musto, P.; Karasz, F. E.; MacKnight, W. J. Hydrogen bonding in polybenzimidazole/polyimide systems: A Fourier-transform infra-red investigation using low-molecular-weight monofunctional probes. Polymer 1989, 30, 1012-1021.

[52] Yan, X. D.; Li, Y.; Xia, T. Black titanium dioxide nanomaterials in photocatalysis. Int. J. Photoenergy 2017, 2017, 8529851.

[53] Naldoni, A.; Allieta, M.; Santangelo, S.; Marelli, M.; Fabbri, F.; Cappelli, S.; Bianchi, C. L.; Psaro, R.; Dal Santo, V. Effect of nature and location of defects on bandgap narrowing in black $\mathrm{TiO}_{2}$ nanoparticles. $\mathrm{J}$. Am. Chem. Soc. 2012, 134, 7600-7603.

[54] Xie, M. L.; Liu, H.; Chun, F. J.; Deng, W.; Luo, C.; Zhu, Z. H.; Yang, M.; Li, Y. M.; Li, W.; Yan, W. et al. Aqueous phase exfoliating quasi2D $\mathrm{CsPbBr}_{3}$ nanosheets with ultrahigh intrinsic water stability. Small 2019, 15, 1901994.

[55] Xi, G. C.; Xiong, K.; Zhao, Q. B.; Zhang, R.; Zhang, H. B.; Qian, Y. T. Nucleation-dissolution-recrystallization: A new growth mechanism for $t$-selenium nanotubes. Cryst. Growth Des. 2006, 6, 577-582.

[56] García-Fernández, A.; Bermúdez-García, J. M.; Castro-García, S.; Llamas-Saiz, A. L.; Artiaga, R.; López-Beceiro, J.; Hu, S.; Ren, W.; Stroppa, A.; Sánchez-Andújar, M. et al. Phase transition, dielectric properties, and ionic transport in the $\left[\left(\mathrm{CH}_{3}\right)_{2} \mathrm{NH}_{2}\right] \mathrm{PbI}_{3}$ organicinorganic hybrid with $2 \mathrm{H}$-hexagonal perovskite structure. Inorg. Chem. 2017, 56, 4918-4927.

[57] Zhang, W.; Ye, H. Y.; Graf, R.; Spiess, H. W.; Yao, Y. F.; Zhu, R. Q.; Xiong, R. G. Tunable and switchable dielectric constant in an amphidynamic crystal. J. Am. Chem. Soc. 2013, 135, 5230-5233. 
[58] Noel, N. K.; Congiu, M.; Ramadan, A. J.; Fearn, S.; McMeekin, D. P.; Patel, J. B.; Johnston, M. B.; Wenger, B.; Snaith, H. J. Unveiling the influence of $\mathrm{pH}$ on the crystallization of hybrid perovskites, delivering low voltage loss photovoltaics. Joule 2017, 1, 328-343.

[59] Seo, H. K.; Kim, G. S.; Ansari, S. G.; Kim, Y. S.; Shin, H. S.; Shim, K. H.; Suh, E. K. A study on the structure/phase transformation of titanate nanotubes synthesized at various hydrothermal temperatures. Sol. Energy Mater. Sol. Cells 2008, 92, 1533-1539.

[60] Kim, J.; Duy, L. T.; Ahn, B.; Seo, H. Pre-oxidation effects on properties of bismuth telluride thermoelectric composites compacted by spark plasma sintering. J. Asian Ceram. Soc. 2020, 8, 211-221.

[61] Fabian, D. M.; Ardo, S. Hybrid organic-inorganic solar cells based on bismuth iodide and 1,6-hexanediammonium dication. J. Mater. Chem. A 2016, 4, 6837-6841.

[62] Yi, N. B.; Wang, S.; Duan, Z. H.; Wang, K. Y.; Song, Q. H.; Xiao, S. M. Tailoring the performances of lead halide perovskite devices with electron-beam irradiation. Adv. Mater. 2017, 29, 1701636.

[63] Dang, Z. Y.; Shamsi, J.; Palazon, F.; Imran, M.; Akkerman, Q. A.; Park, S.; Bertoni, G.; Prato, M.; Brescia, R.; Manna, L. In situ transmission electron microscopy study of electron beam-induced transformations in colloidal cesium lead halide perovskite nanocrystals. ACS Nano 2017, 11, 2124-2132.

[64] Liu, J.; Liu, Y.; Liu, N. Y.; Han, Y. Z.; Zhang, X.; Huang, H.; Lifshitz, Y.; Lee, S. T.; Zhong, J.; Kang, Z. H. Metal-free efficient photocatalyst for stable visible water splitting via a two-electron pathway. Science 2015, 347, 970-974.

[65] Even, J.; Pedesseau, L.; Jancu, J. M.; Katan, C. Importance of spin-orbit coupling in hybrid organic/inorganic perovskites for photovoltaic applications. J. Phys. Chem. Lett. 2013, 4, 2999-3005.

[66] Umari, P.; Mosconi, E.; De Angelis, F. Relativistic GW calculations on $\mathrm{CH}_{3} \mathrm{NH}_{3} \mathrm{PbI}_{3}$ and $\mathrm{CH}_{3} \mathrm{NH}_{3} \mathrm{SnI}_{3}$ perovskites for solar cell applications. Sci. Rep. 2014, 4, 4467.

[67] Liang, J.; Wang, C. X.; Wang, Y. R.; Xu, Z. R.; Lu, Z. P.; Ma, Y.; Zhu, H. F.; Hu, Y.; Xiao, C. C.; Yi, X. et al. All-inorganic perovskite solar cells. J. Am. Chem. Soc. 2016, 138, 15829-15832.

[68] Grätzel, M. Photoelectrochemical cells. Nature 2001, 414, 338-344.

[69] Hagiwara, H.; Nozawa, I.; Hayakawa, K.; Ishihara, T. Hydrogen production by photocatalytic water splitting of aqueous hydrogen iodide over Pt/alkali metal tantalates. Sustain. Energy Fuels 2019, 3, 3021-3028.

[70] Powers, D. C.; Anderson, B. L.; Hwang, S. J.; Powers, T. M.; Pérez, L. M.; Hall, M. B.; Zheng, S. L.; Chen, Y. S.; Nocera, D. G. Photocrystallographic observation of halide-bridged intermediates in halogen photoeliminations. J. Am. Chem. Soc. 2014, 136, 1534615355.

[71] Han, C.; Zhu, X. L.; Martin, J. S.; Lin, Y. X.; Spears, S.; Yan, Y. Recent progress in engineering metal halide perovskites for efficient visiblelight-driven photocatalysis. ChemSusChem 2020, 13, 4005-4025. 